\title{
Sensing Properties of Tin Acetylacetonate-Based Thin Films Doped with Platinum
}

\author{
Přemysl Fitl*,1,3, Vladimír Myslík², Martin Vrňata1 ${ }^{1}$, Josef Náhlík², \\ Dušan Kopecký ${ }^{1}$, Jan Vlček ${ }^{1}$, Jaroslav Hofmann ${ }^{1}$ and Ján Lančok ${ }^{3}$ \\ ${ }^{1}$ Department of Physics and Measurements, Institute of Chemical Technology, \\ Technická 5, 166 28, Prague 6, Czech Republic \\ ${ }^{2}$ Department of Solid-State Engineering, Institute of Chemical Technology, \\ Technická 5, 166 28, Prague 6, Czech Republic \\ ${ }^{3}$ Institute of Physics, Academy of Sciences of the Czech Republic, \\ Na Slovance 2, 18221 Prague 8, Czech Republic
}

(Received November 16, 2010; accepted March 11, 2011)

Key words: gas sensing, tin acetylacetonate, pulsed laser deposition (PLD) method, selectivity tunable by temperature

Thin sensing films based on tin acetylacetonate (SnAcAc) with a platinum catalyst were prepared in situ by pulsed laser deposition (PLD) with a Nd:YAG laser. The morphology and roughness of both as-deposited and annealed layers were characterized. These layers were also deposited on alumina sensor substrates with interdigital $\mathrm{Pt}$ electrodes and then used for the detection of hydrogen, $n$-butanol, toluene, and water vapors in synthetic air. The temperature dependence of the response of the prepared sensors was measured in the range of $40-350^{\circ} \mathrm{C}$. It was proved that the selectivity to the above mentioned gases is easily tunable by adjusting the operating temperature of the sensor. The maximum response was achieved at $110^{\circ} \mathrm{C}$ for hydrogen, $220^{\circ} \mathrm{C}$ for $n$-butanol, $300^{\circ} \mathrm{C}$ for toluene, and $340^{\circ} \mathrm{C}$ for water vapor. The activation energy of surface reactions taking place during the detection process was also calculated.

\section{Introduction}

Pulsed laser deposition (PLD) is commonly used for the deposition of both inorganic and organic substances. The high flexibility of this method allows us to carry out the deposition of multilayer or mixed structures in situ in one technological step. Prepared layers exhibit high porosity resulting in a large specific surface, which is advantageous

*Corresponding author: e-mail: fitlp@vscht.cz 
for gas sensing applications. When depositing catalytic metal by PLD, it is possible to create metallic nanoparticles or islands with dimensions even in the order of nanometers. ${ }^{(1-3)}$ Such a dispersion of the catalyst ensures a high concentration of active sites on which elementary steps of detection take place.

It is well known that plasma depositions of metal acetylacetonates lead to the polymerization of molecules of acetylacetonic ligands, which is connected with a significant increase in thermal stability and with a very good response to reducing gases. ${ }^{(4-6)}$ According to our previous experience, ${ }^{(7,8)}$ the layers also prepared from acetylacetonates by the PLD method (where the deposited material is transferred through a plasma plume) are thermally stable and simultaneously sensitive to hydrogen, alcohol vapors, and ozone, for example.

Considering the detection of different gases or gas mixtures, the selectivity of sensors is a complex problem. There is a possibility of improving the sensor selectivity by setting its operating temperature. The higher the reactivity of detected gas (represented by the low activation energy for the surface chemical reaction), the lower the sensor operating temperature suitable to achieve maximum response and vice versa.

In this work, we investigated laser-deposited SnAcAc-based layers containing embedded Pt catalyst from the following viewpoints: (a) content of platinum in the layers; (b) layer morphology studied by scanning electron microscopy (SEM) and atomic force microscopy (AFM); determination of layer roughness; (c) values of sensor parameters (layer resistance, dc response, sensing dynamics, activation energy of surface reactions) and their dependence on operating temperature as well as on the nature of the tested gas.

\section{Materials and Methods}

The sensing films were deposited from pure SnAcAc (pressed powder, SigmaAldrich, reagent grade) and platinum (bulk metal, purity 99.99\%) targets by the PLD method. The 4th harmonic frequency of the Nd:YAG laser (Quantel Brilliant) at a wavelength of $266 \mathrm{~nm}$, pulse duration of $4 \mathrm{~ns}$, and repetition rate of $10 \mathrm{~Hz}$ was used. The sensitive layers were prepared in two steps: (i) deposition from the SnAcAc target with 1,500 pulses (resulting equivalent thickness is approximately $350 \mathrm{~nm}$ ) followed by (ii) deposition from the Pt target with 500 pulses (representing an equivalent thickness of approximately $4 \mathrm{~nm}$ ). The energy density of the laser beam was $0.6 \mathrm{~J} \mathrm{~cm}^{-2}$ in the case of the SnAcAc target and $4.0 \mathrm{~J} \mathrm{~cm}^{-2}$ for the Pt target. The deposition took place under nitrogen $(5 \mathrm{~Pa})$ atmosphere. It is well known that the as-deposited layers of acetylacetonates exhibit very high electric resistance, so the next necessary technological step includes their activation in order to acquire gas sensing properties. ${ }^{(4,5,7,8)}$ The thermal activation process developed in our laboratory, i.e., treatment by controlled heating in a furnace (up to $400^{\circ} \mathrm{C}, 9 \mathrm{~h}$, synthetic air atmosphere containing 5,000 ppm hydrogen), is discussed in detail in a previous work. ${ }^{(9)}$

The depositions were carried out on three types of substrate: (a) glass slides (samples for SEM and energy-dispersive X-ray analysis), (b) polished silicon wafers (samples for AFM analyses), (c) alumina sensor substrates equipped with interdigital Pt contacts on one side and resistance heating on the opposite side (measurement of response to various gases). 
The presence and content of platinum in the layers were analyzed by energydispersive X-ray (EDX) analysis. The microstructure of the prepared layers was studied by scanning electron microscopy (SEM). Both these analyses were carried out on a Philips XL30 CP instrument equipped with a detector of secondary electrons and the EDX detector PV 9760. The accelerating voltage ranged from 5 to $25 \mathrm{kV}$, depending on the thickness of the deposited layer.

The surface morphology and average roughness $(R a)$ of the samples were examined using an atomic force microscope (Digital Instruments CP II Veeco) working in the contact mode with silicon P-doped probes CONT20A-CP and a spring constant of $0.9 \mathrm{~N} / \mathrm{m}$.

Surface roughness was also measured using a confocal microscope (Olympus Lext OLS 3100) in order to obtain the values of $R a$ by a noncontact optical method.

The prepared sensitive layers with Pt catalyst were tested for hydrogen, toluene, n-butanol, and water vapor detection. The testing proceeded in special measuring equipment developed in our laboratory. ${ }^{(7,8)}$ This system measures the resistance values automatically and calculates the dc response in relation to the sensor temperature or concentration of detected gas. It also enables us to process and analyze the measured data, and to fit them with a suitable function. During measurements, the atmosphere was switched every 2 min from "pure" synthetic air to synthetic air containing the detected gas and vice versa. The values of sensor resistance were logged each second. Dc response to the tested gas (at the defined concentration and operating temperature) was calculated as the ratio of the sensor electrical resistance in a reference atmosphere of "pure" synthetic air $\left(R_{0}\right)$ to its electrical resistance $(R)$ in synthetic air containing the detected gas: ${ }^{(7,8)}$

$$
S_{\mathrm{dc}}=R_{0} / R
$$

In order to better describe the chemical processes during detection, the activation energy $\left(E_{\mathrm{a}}\right)$ of surface reactions was determined. Activation energy is a certain measure of the reactivity of detected gases; there is also a correlation between $E_{\mathrm{a}}$ values and the temperature of the response maximum. Several references deal with the calculation of activation energy on oxidic materials of the active layer (tin oxide, titanium dioxide, indium sesquioxide with catalysts). ${ }^{(10-12)}$ To the best of our knowledge, no estimation of activation energy for layers based on acetylacetonates has been published to date. In this manuscript, the activation energy was computed by solving the model of the first-order reaction according to ref. 12 .

When the concentration of the detected gas is kept constant, the reaction rate depends (at a given thermodynamic temperature $T$ of the sensor) only on the concentration of free active sites:

$$
-\frac{\mathrm{d} c_{\mathrm{x}}}{\mathrm{d} \tau}=k c_{\mathrm{x}}[T=\text { const. }]
$$

where $c_{\mathrm{x}}$ is the concentration of free active sites, $\tau$ is time, and $k$ is a temperaturedependent rate constant of the surface reaction. The quantity $c_{\mathrm{x}}$ is nominally measurable; 
however, one can assume that the change in this quantity corresponds to the change in the sensor resistance $(R) .^{(12)}$ After integration with boundary and starting conditions, where when $\tau=0$, then $c_{\mathrm{x}}$ is proportional to $R_{0}$ (starting resistance of the sensor), and when $\tau=\tau^{\prime}$, then $c_{\mathrm{x}}{ }^{\prime}$ is proportional to $R$ (resistance of a sensor after a sudden change in atmosphere), we obtain the following expression for the rate constant $k$ as a function of sensor resistance:

$$
k \tau=\ln \left(\frac{R_{0}}{R}\right)
$$

Activation energy $E_{\mathrm{a}}$ was then assumed to enter the Arrhenius equation for the temperature dependence of the rate constant:

$$
k=Z \exp \left(-\frac{E_{\mathrm{a}}}{B T}\right)
$$

where $Z$ is a pre-exponential factor, $B$ is the Boltzmann constant, and $T$ is the thermodynamic temperature of the sensor. Hence, activation energy $E_{\mathrm{a}}$ can be obtained if the rate constant is known at least for two different temperatures.

The dynamic properties of the prepared sensors were characterized from the following model. The time dependence of the sensor resistance, i.e., quantity $R(\tau)$, can be expressed from eq. (3) as

$$
R(\tau)=R_{\infty}-\left(R_{\infty}-R_{0}\right) \exp (-k \tau)
$$

where $R_{\infty}$ is a steady-state resistance of the sensor (after atmosphere switching). This model is derived under the assumption of a first-order reaction. On the basis of extensive experimental data $R(\tau)$ obtained for each sensor, three characteristic parameters, $R_{0}$, $R_{\infty}$, and $k$, were fitted. In the next step, the parameters "computed response (2 min)" and "computed response (10 $\mathrm{min})$ ” were extrapolated from model eq. (5) to subsequent 2 or $10 \mathrm{~min}$ following each atmosphere switching. The difference between these calculated parameters and "real time response" obtained from eq. (1) can provide useful information, i.e., whether the sensing layer achieves a steady state for a given testing gas and switching interval.

\section{Results}

\subsection{Chemical composition of prepared layers}

Compositions (in atomic percent) of the SnAcAc source, as-deposited layer, and the layer after annealing are summarized in Table 1. Microprobe analysis proved the presence of Pt in the deposited layers. The quantity of Pt in the as-deposited layer is rather small considering the fact that there were 1,500 pulses from the SnAcAc target and 500 pulses with a significantly higher energy density from the Pt target during the 
deposition. The as-deposited layer is relatively rich in carbon, but during the activation process, the relative content of carbon rapidly decreases, as carbon escapes in the form of volatile compounds.

The detailed investigation of FTIR spectra of the PLD-deposited layers from the SnAcAc source (both as-deposited and after thermal activation) was reported in ref. 9. The above-mentioned "escape" of carbon during the activation process, accompanied by the partial transformation of SnAcAc to tin carboxylate, was also reported in ref. 9.

\subsection{Morphology and roughness}

SEM images of as-deposited layers and the layers after activation (annealing) are presented in Figs. 1 and 2, respectively. Layer morphology in the as-deposited state could be described as homogeneously deployed wrinkled hills originating from the laser-induced plasma polymerization of SnAcAc. It is apparent that after activation,

Table 1

Elemental composition of the layers (in atomic \%).

\begin{tabular}{lccc}
\hline & \multicolumn{3}{c}{ Material } \\
\cline { 2 - 4 } Element & Pure SnAcAc & As-deposited layer & After annealing \\
\hline Sn & 3.23 & 2.13 & 7.51 \\
$\mathrm{C}$ & 32.26 & 30.45 & 28.11 \\
$\mathrm{Pt}$ & 0 & 0.08 & 0.63 \\
Ratio C/Sn & 10.0 & 14.3 & 3.74 \\
\hline
\end{tabular}
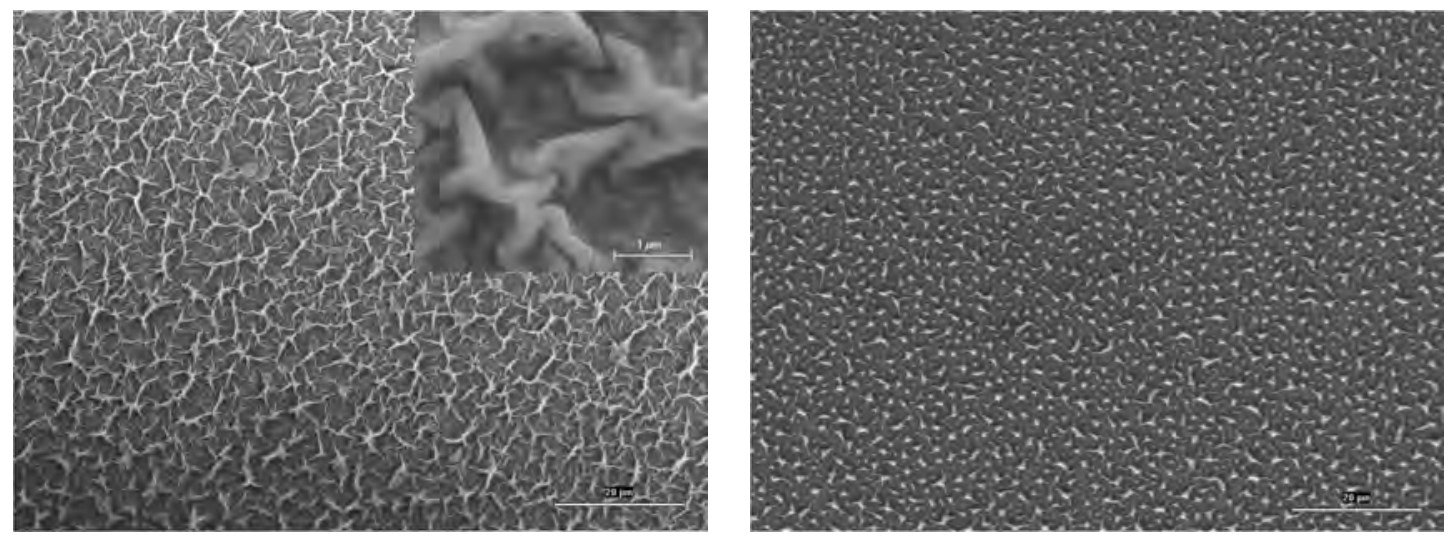

Fig. 1 (left). Surface morphology of as-deposited tin acetylacetonate/Pt layer.

Fig. 2 (right). Surface morphology of laser-deposited tin acetylacetonate/Pt layer after activation process (annealing at $400^{\circ} \mathrm{C}$ for $4 \mathrm{~h}$ in synthetic air). 
the layer surface becomes less wrinkled (less structured) and smoother, but the layer remains compact. This is probably a result of polymeric material creeping taking place at elevated temperature.

AFM portraits of the same layers are shown in Figs. 3 and 4. Because the analyzed area is significantly smaller than in the SEM images, the AFM portraits show details of the above-mentioned wrinkled hills. Although the SEM images before and after the activation process look different, repeated AFM scan of the surface shows the same character of layer morphology at small scales. Table 2 shows the average roughness of the samples before and after the activation process. $R a$ was measured using a confocal microscope and AFM in an area of $50 \times 50 \mu \mathrm{m}^{2}$. It is also important that the $R a$ values obtained by contact and noncontact methods are comparable (i.e., the deposited organic

(a)

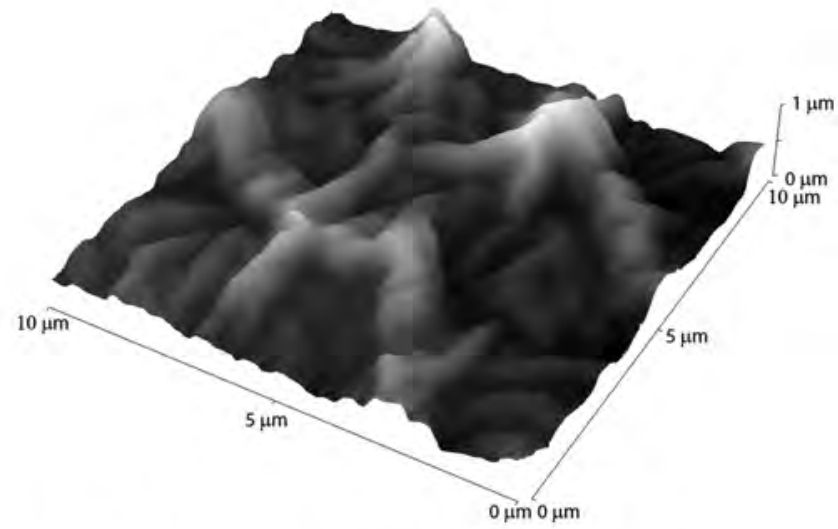

(b)

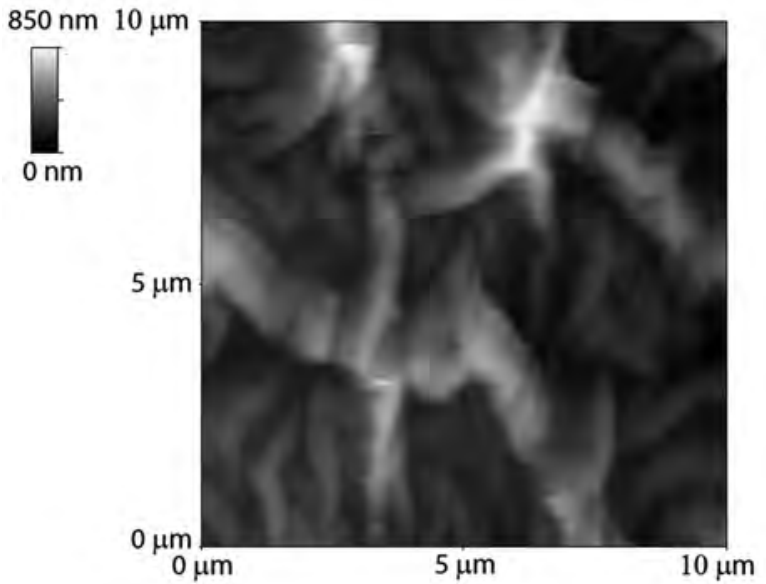

Fig. 3. AFM portrait of as-deposited tin acetylacetonate/Pt layer. 
(a)
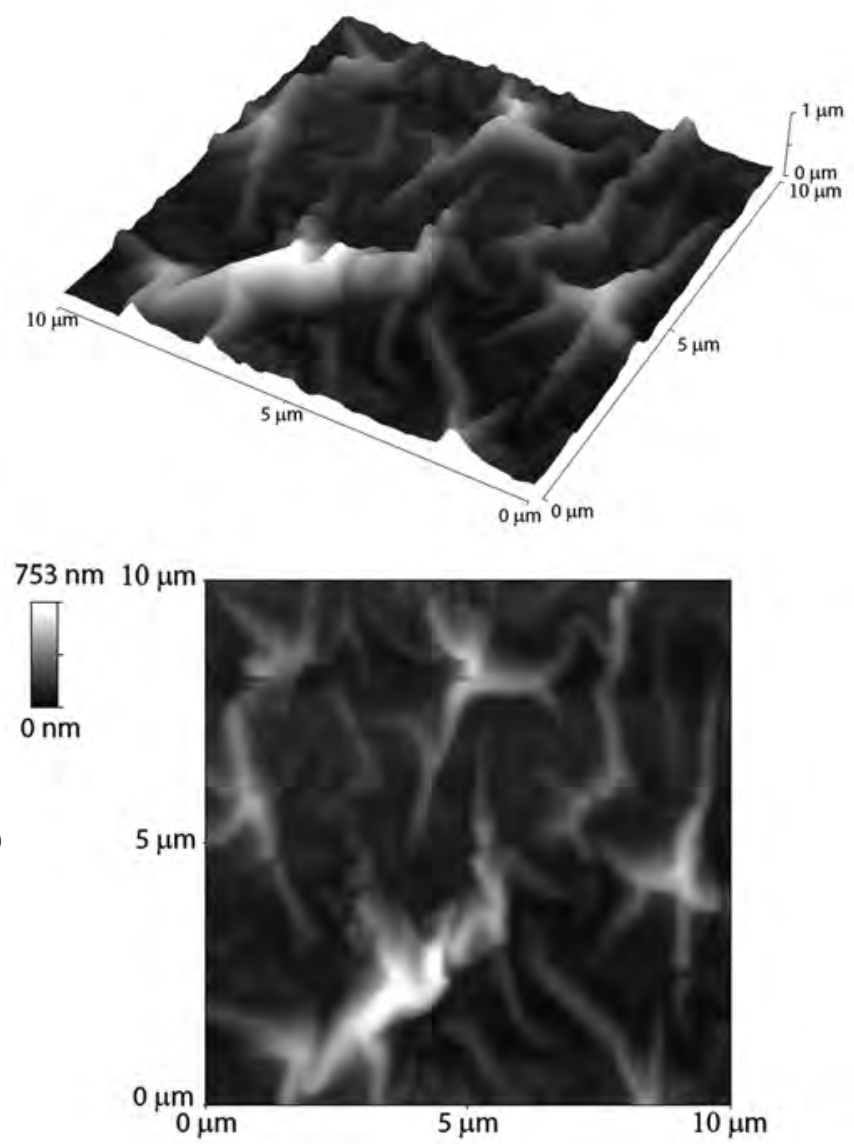

Fig. 4. AFM portrait of laser deposited tin acetylacetonate/Pt layer after activation process (annealing at $400^{\circ} \mathrm{C}$ for $4 \mathrm{~h}$ in synthetic air).

Table 2

Roughness of the layers (in nm).

\begin{tabular}{lcc}
\hline & As-deposited layer & After annealing \\
\hline Confocal microscope & 107 & 80 \\
AFM & 102 & 84 \\
\hline
\end{tabular}

material is sufficiently "hard" and fixed to the substrate). The decrease in roughness after activation, apparent in Table 2, also indicates the above-mentioned creeping. 


\subsection{Sensing properties of prepared sensors}

Figures 5-9 show the sensing response of SnAcAc/Pt layers to various gases and vapors. The labels have the following meanings. "Resistance" represents changes in measured resistance values during the whole measurement process. "Response" is evaluated according to eq. (1) from the last ten resistance values logged immediately before atmosphere change. This parameter is a "real-time" response of the sensor. The "computed response (2 min)" and "computed response (10 min)" were extrapolated according to model eq. (5) to the next 2 or 10 min following atmosphere switching.

The temperature of response maxima $\left(T_{\max }\right)$ was observed to be $110^{\circ} \mathrm{C}$ for hydrogen (Figs. 5-6), $220^{\circ} \mathrm{C}$ for $n$-butanol (Fig. 7), $300^{\circ} \mathrm{C}$ for toluene (Fig. 8), and $340^{\circ} \mathrm{C}$ for water vapor (Fig. 9). In the detection of hydrogen at operating temperatures higher than approx. $150^{\circ} \mathrm{C}$, $2 \mathrm{~min}$ is sufficient for the sensor response to achieve a steady state. In contrast, in the case of $n$-butanol, the model shows that the sensor response does not reach the steady state in 2 min for any temperature. In such a situation, the response can be improved by prolonging the gas switching time. In the case of the detection of toluene and water vapor, there is some discrepancy as the "computed response (10 min)" is slightly lower than the real-time response. This is probably due to the higher complexity of the mechanism underlying the detection process mechanism than that corresponding to a first-order reaction.

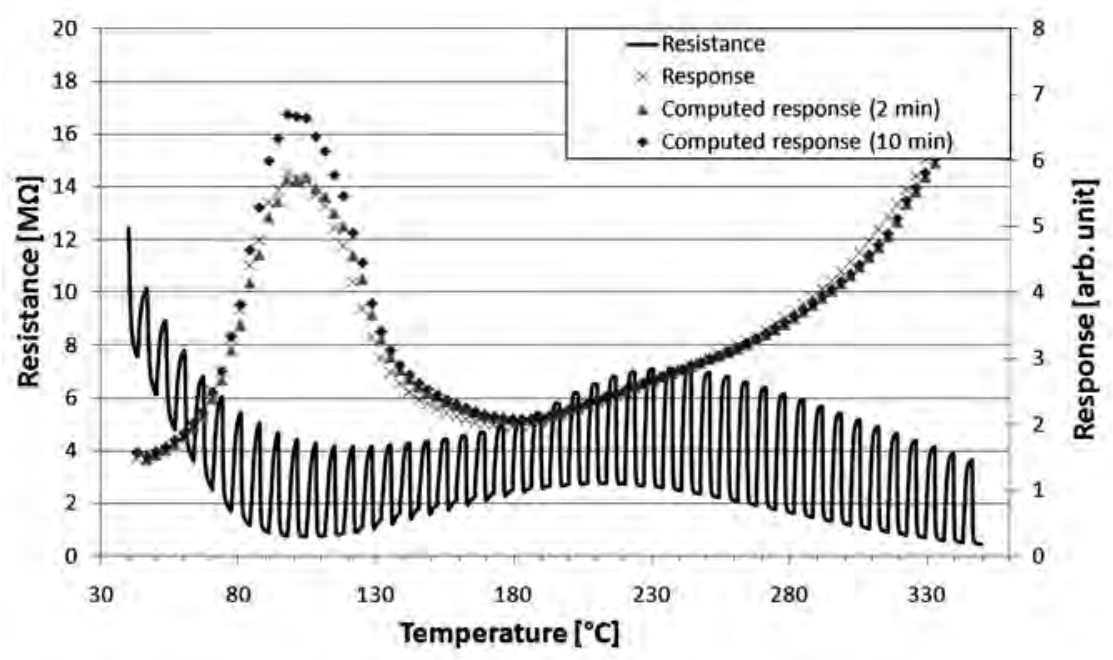

Fig. 5. Temperature dependence of resistance and response to 1,000 ppm of hydrogen (reference gas synthetic air). 


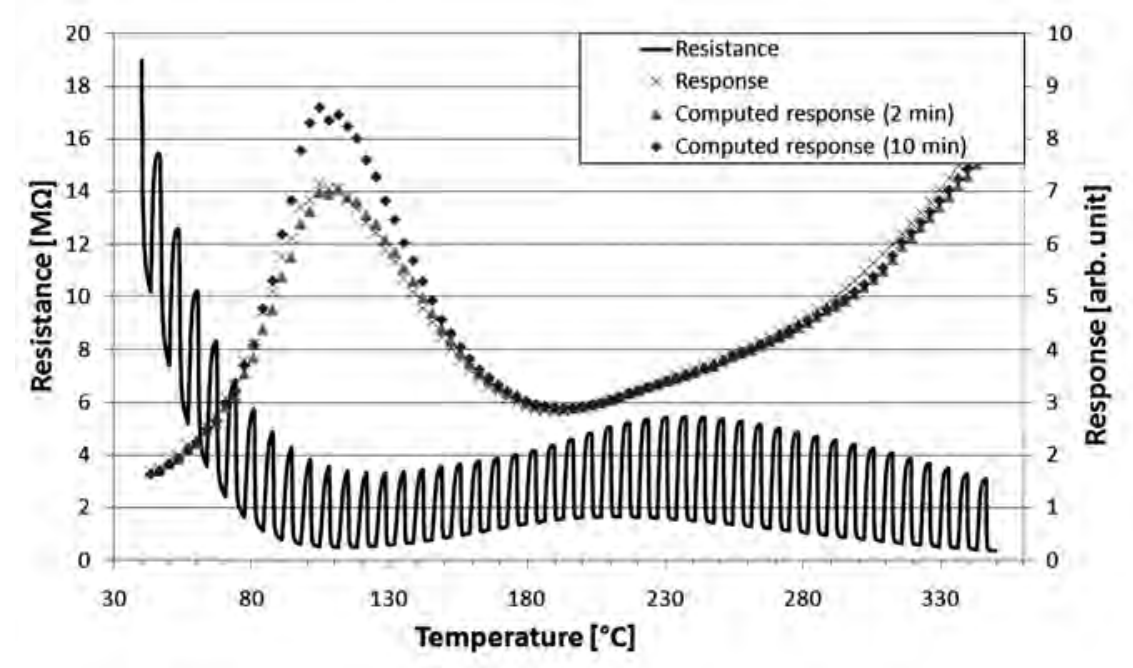

Fig. 6. Repeated measurement of resistance and response to 1,000 ppm of hydrogen (the same conditions as in Fig. 3; delay between measurements, 5 h).

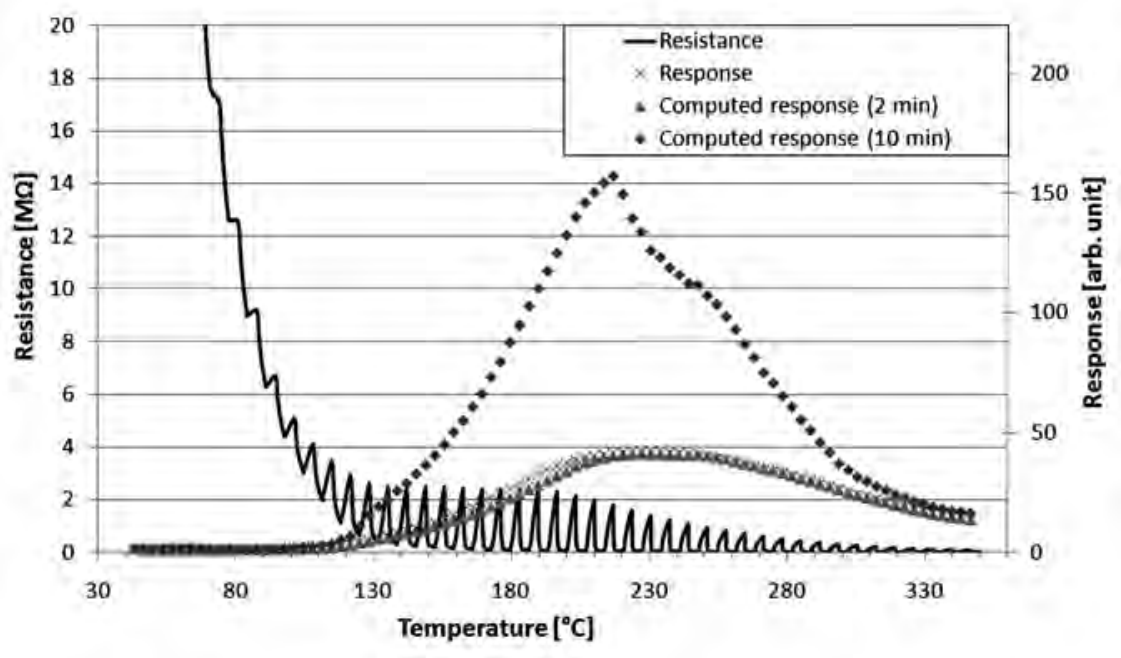

Fig. 7. Temperature dependence of resistance and response to 10,000 ppm $n$-butanol vapor (reference gas: synthetic air). 


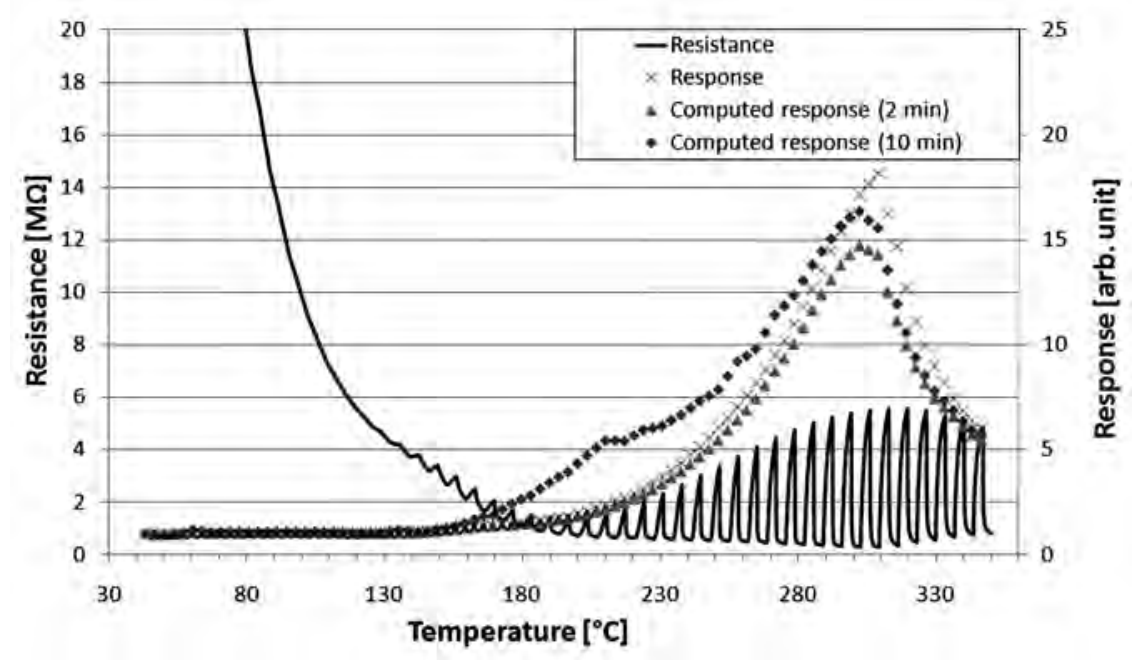

Fig. 8. Temperature dependence of resistance and response to 10,000 ppm toluene vapor (reference gas: synthetic air).

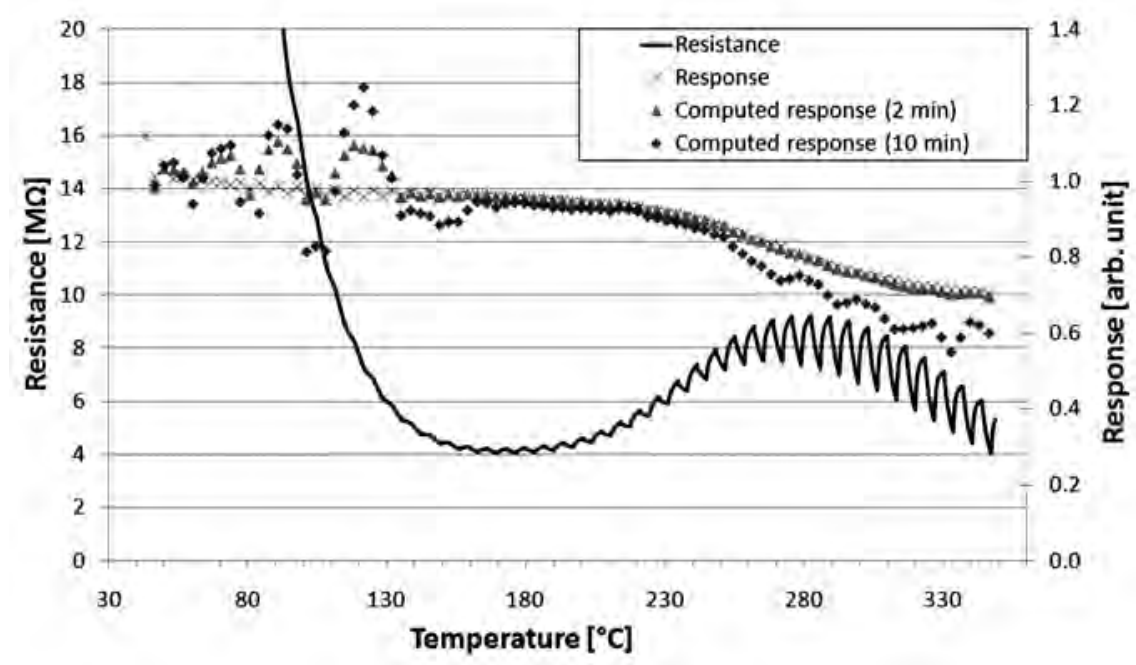

Fig. 9. Temperature dependence of resistance and response to 10,000 ppm water vapor (reference gas: synthetic air). 
According to eq. (4) we also obtained the following activation energies of the detection process (detection proceeds on a sensitive SnAcAc layer containing platinum): $0.428 \mathrm{eV}$ for hydrogen, $0.891 \mathrm{eV}$ for $n$-butanol, $2.322 \mathrm{eV}$ for toluene, and $2.558 \mathrm{eV}$ for water vapor. According to ref. 12, the computed activation energy for the detection of hydrogen on a sensitive $\mathrm{SnO}_{2}$ layer containing platinum is $0.053 \mathrm{eV}$.

The repeatability of the sensor response is another important parameter. It was tested by a second temperature scan measurement delayed for $5 \mathrm{~h}$ after the first one. The relative difference between the measured values of the response was less than $15 \%$ for all the tested gases. Figures 5 and 6 illustrate the reproducibility in the case of hydrogen sensing.

\section{Discussion and Conclusions}

The layers described in this article were prepared by an original technological procedure comprising the pulsed laser deposition of an active layer from acetylacetonate targets (i.e., laser-induced plasma polymerization) with the subsequent deposition of a catalyst in one technological step. Annealing (activation) of the as-deposited layers led to their thermodynamical and structural stabilization and also ensured a good stability under the operating conditions of the sensor.

From the practical point of view it is important that the layers have clearly differentiated temperatures of response maxima to distinct gases: $T_{\max }=110^{\circ} \mathrm{C}$ for hydrogen, $T_{\text {max }}=220^{\circ} \mathrm{C}$ for $n$-butanol, $T_{\max }=300^{\circ} \mathrm{C}$ for toluene, and $T_{\max }=340^{\circ} \mathrm{C}$ for water vapour. Such properties are highly benefitial for use in multisensor arrays, so only one kind of active layer is sufficient for this purpose. The selectivity can then be ensured by setting only the operating temperature.

The sensor also enables us to distinguish between the response to hydrogen, $n$-butanol, and toluene on one side and water vapor on the other side. Hydrogen, $n$-butanol, and toluene behave like reducing agents during detection; an inverse response was observed in the case of water vapor. The prepared sensors were also tested for long-term stability (their response was periodically observed for one year). During this period, the sensors exhibit the same operating-temperature-related selectivity. On the basis of these findings, we judge our sensors to be suitable for application in practice.

\section{Acknowledgements}

This work was supported by projects funded by the Ministry of Education of the Czech Republic (Nos. MSM 6046137302 and MSM 6046137306) and a project of the Czech Science Foundation no. P108/11/1298. One of the authors (P. Fitl) is grateful to Vakuum Praha for funding his junior research "Vacuum evaporation of organic substances for chemical sensors". 


\section{References}

1 M. García Del Muro, Z. Konstantinovic, M. Varela, X. Batlle and A. Labarta: J. Nanomater. 2008 (2008) doi:10.1155/2008/475168.

2 N. Savastenko, H.-R. Volpp, O. Gerlach and W. Strehlau: J. Nanopart. Res. 10 (2008) 277.

3 F. E. Kruis, H. Fissan and A. Peled: J. Aerosol. Sci. 29 (1998) 511.

4 N. Inagaki, S. Tasaka and Y. Nozue: J. Appl. Polym. Sci. 45 (1992) 1041.

5 N. Inagaki, S. Tasaka and M. Kobayashi: Polym. Bull. 25 (1991) 273.

6 T. Takada, K. Suzuki and M. Nakane: Sens. Actuators, B 13 (1993) 404.

7 M. Vrňata, V. Myslík, F. Vysloužil, M. Jelínek, J. Lančok and J. Zemek: Sens. Actuators, B 71 (2000) 24.

8 V. Myslík, F. Vysloužil, M. Vrňata, Z. Rozehnal, M. Jelínek, R. Fryček and M. Kovanda: Sens. Actuators, B 89 (2003) 205.

9 V. Myslík, M. Vrňata, F. Vysloužil, M. Jelínek and M. Novotná: J. Appl. Polym. Sci. 74 (1999) 1614.

10 M. N. Rumyantseva, E. A. Makeeva, S. M. Badalyan, A. A. Zhukova and A. M. Gaskov: Thin Solid Films 518 (2009) 1283.

11 O. A. Maslova, E. A. Makeeva, M. N. Rumyantseva and A. M. Gaskov: Inorg. Mater. 45 (2009) 1153.

12 A. Helwig, G. Müller, G. Sberveglieri and G. Faglia: Sens. Actuators, B 130 (2008) 193. 